\title{
RESEARCH QUESTION: PERIODONTAL DISEASES STATUS IN SCHOOL CHILDREN OF JAIPUR (RAJ) INDIA
}

Rashmi Gupta ${ }^{1}$,Kusum Lata Gaur ${ }^{2}$,Akhil Sharma ${ }^{3}$,Afifa Zafer ${ }^{4}$,Dilip raj ${ }^{5}$.

\section{HOW TO CITE THIS ARTICLE:}

Rashmi Gupta, Kusum Lata Guar, Akhil Sharma, Afifa Zafer, Dilip Raj, "Research Question: Periodontal Diseases Status in School Children of Jaipur, (Raj) India". Journal of Evolution of Medical and Dental Sciences 2013; Vol2, Issue 28, July 15; Page: 5270-5276.

OBJECTIVES: To find out prevalence of periodontal diseases and its associating factors among students : METHODOLOGY: A cross-sectional observational study was carried out on 3200 children of 5-16 years of age of 20 elementary schools of urban and rural area of Jaipur in year 2011. Socio-demographic data were collected from parents of children and thorough dental checkup was arranged by a dentist for these children. Children with Periodontal diseases were identified. Data in details were collected as per pre-designed proforma. Data collected were analyzed and inferred with chi-square test. RESULT: $29.31 \%$ of children were diagnosed as having periodontal diseases. Periodontal diseases was significantly $(\mathrm{P}<0.001)$ lesser in rural areas $(27.94 \%)$ than in the urban areas (47.38\%). Variation in proportion of cases as per the age and sex was also found to be highly significant $(\mathrm{P}<0.001)$. CONCLUSION: More than one third students were having periodontal diseases. It was found associated with the type of areas, age and sex but water, mouth rinsing and frequency of cleansing was not associated with periodontal diseases.

KEY WORDS: Periodontal diseases, Socio-demographic factors and chi-square Test,

INTRODUCTION: Periodontal diseases are one of the most widespread diseases in the world and are more prevalent in developing countries, particularly in rural areas. They have been reported to appear at an early age in developing countries and progress with age ${ }^{1}$. More than 90 percent of adults after attaining the age of 30 years suffer from periodontal disease which also has its inception in childhhod. ${ }^{2}$ Prevalence of gum disease in children is very high worldwide, with the majority of children being affected.$^{3}$

Surveys indicated that loss of periodontal attachment and supporting bone is relatively uncommon in the young but the incidence increases in adolescents aged 12 to 17 years when compared to children aged 5 to 11years. In India, Dr. Jain ${ }^{4}$ had reported $12.4 \%$ periodontal diseases in 1979. Another author Dr. S.P. Roa ${ }^{5}$ had reported $17.8 \%$ in 1993 . These epidemiological studies indicate that the prevalence of periodontal diseases is increases with the time. Despite this prevalence, children and adolescents should receive periodic periodontal evaluation as a component of routine dental visits. Gingivitis (the first stage of periodontal disease) is nearly universal in children and adolescents. Studies indicate that nearly all children and adolescents have gingivitis. Advanced forms of periodontal disease are rarer in children than adults. ${ }^{6}$

MATERIALS AND METHODS:The present Cross Sectional Observational study was carried out in year 2010 on 3200 School going children aged 5-16 years. As per Department of Education, Jaipur District has four urban blocks; namely Jaipur East, Jaipur West, Jhotwara and Sanganer. Out of these Jaipur west and Jhotwara were selected randomly for the study. Likewise the rural area of Jaipur 
District is constituted by 13 Panchayat Samities, out of that two Amber and Jamwaramgarh were selected randomly for the study.

Sample size: Sample size was calculated 1600 subjects at $95 \%$ confidence limit with $10 \%$ allowable error assuming $20 \%$ prevalence of periodontal diseases. So for the study purpose 1600 children from schools of rural areas and 1600 children from schools of urban areas was included in study. List of rural and urban schools in the selected area was procured from the office of Deputy Director of Education Department of Jaipur District. Schools were also selected randomly using the simple random technique from the procured list to achieve the desired sample size i.e. 1600 from rural and 1600 from urban areas.

Every Institutional Head of identified school was informed about the purpose and methodology of the study and those who had given consent were given the consent form and proforma for parents. $1^{\text {st }}$ part of the designed proforma consisting general information about the child and his family was given to parents of the child through the respective class teachers. After the forms were duly filled up by the parents of the study subjects, it was subsequently collected from the class teachers. Identified Schools were visited on the mutually pre-decided date and time so as to examine the maximum number of study subjects by a dentist. Children were examined in the school premises at a suitable place in presence of respective class teachers with the subjects seated in ordinary chairs in natural day light for illumination, avoiding direct sunlight.

Finally the screened students were examined thoroughly for dental and periodontal diseases, after reassuring them and making them comfortable and taking all necessary aseptic precautions. Part second of the predesigned proforma was filled after examining each child. The same procedure was in identified schools till the sample size of 1600 students of rural and 1600 students of urban area were achieved.

Dentition status and treatment need was assessed using Oral Health Assessment Form $2004^{7}$ by a dentist. Only relevant information related with periodontal diseases along with general information was collected on predesigned proforma.

Data thus collected were compiled, analyzed with Microsoft excel 2007.

To find out significance of difference in proportion chi-square test was used.

RESULTS: The present study has been designed to find out associating factors of periodontal diseases amongst 3200 students in 5-16 years of age group studying in elementary schools of Jaipur district. $\quad$ Periodontal diseases was found in 938 (29.31\%) surveyed students.

Present study revealed that rural children had significantly more $(\mathrm{p}<0.001)$ periodontal diseases than the urban children i.e. $34.56 \% \mathrm{v} / \mathrm{s} 24.06 \%$.

Further it is revealed that difference in distribution of periodontal diseases cases proportion according to age was also having highly significant variation $(p<0.001)$ showing maximum proportion in the age groups of 11-13 years,14-16 years,8-10 years and followed by 5-7 years of age groups.

Present study also found that males predominated in having periodontal diseases than male children and it was significant.

It was also observed in this study that the difference in distribution of periodontal diseases cases according to mother's education was significant $(\mathrm{p}<0.001)$ but as per father's education it was not 
$(p=0.95)$. It was observed that as education increases proportion of periodontal diseases cases decreases.

When water source for drinking was asked, it was not found significant. In the present study although mouth rinsing and frequency of teeth cleaning were not associated with periodontal diseases $(p=0.09)$ but periodontal diseases was observed significantly associated $(p<0.001)$ with type of material used for teeth cleaning with maximum cases in children who used fingers and minimum in children who clean their teeth with tooth paste.

DISCUSSION: Out of 3200 children, 938 (29.31\%) were suffering from periodontal disease from which (34.56\%) hailed from the rural areas and (24.06\%) from the urban areas as assessed by Community Periodontal Index. Significant $(\mathrm{P}<0.001)$ variation was observed in the proportion of the periodontal disease cases which were more in urban area. These findings are similar to the findings of Benoît Varenne (2004), ${ }^{8}$ Rao SP $(1993)^{5}$ and this may be due to the poor oral hygiene in the rural areas 9 . In India, there is no oral health care system in the rural areas with the dentist: population ratio of about 1:2,00,000. There is no paradental infrastructure at village level and the primary health care centre level. At community health care centre level only $25 \%$ community health centers have a dental surgeon but they too have inadequate instruments, equipments and dental materials. Good oral health care infrastructure and easy access to the services available at village/primary health centre level has been shown to effect prevalence of periodontal diseases ${ }^{10}$. Better periodontal health was observed in urban than in the rural areas, this may be because of the more number of dentists in urban areas. Majority of the hospitals and teaching institutions are also located in the urban areas.

In this study, almost half (41.34\%) of children with periodontal diseases were from the 1113 years of age group followed by $14-16$ years of age (30.39\%), 8-10 years $(24.50 \%)$ and 5-7 years $(8.21 \%)$ respectively. Significant $(\mathrm{P}<0.001)$ variation was observed in proportion of the periodontal disease cases in different age groups. Similar pattern was also observed by Goel P et al (2000)11, Jose et al. in (2003), ${ }^{12}$ Dhar V et al (2007), ${ }^{13}$ UM Das (2009) ${ }^{14}$ Deepak (2010) ${ }^{15}$

This could be explained due to the presence of mixed dentition, varied food habit, shedding of primary teeth, improper and unsupervised oral hygiene practices and malocclusions. ${ }^{16}$ The general trend observed in the majority of the studies was, increasing severity with increasing age $(7,15,17,29,35,43)$. Ageing is a natural process and changes are there in host immunity against disease process but if one can practice optimum oral hygiene, he or she can maintain healthy teeth throughout life. Increasing severity may be because of the untreated cumulative effect of disease process over the period of time. ${ }^{5}$ Periodontal disease may increase during adolescence, due to lack of motivation to practice oral hygiene. Children who maintain good oral health habits until the teen years are more likely to continue brushing and flossing than children who were not taught proper oral care. Hormonal changes related to puberty can put teens at greater risk for getting periodontal disease. During puberty, an increased level of sex hormones, such as progesterone and possibly estrogen, cause an increased blood circulation to the gums. This may cause an increase in the gum's sensitivity and lead to a greater reaction to any irritation, including food particles and plaque. During this time, the gums may become swollen, turn red and feel tender. ${ }^{17}$

Periodontal disease was observed more in males (33.52\%) as compared to females (25\%),and this difference was found to be statistically significant. This finding was supported by 
Goel P et al(2000) ${ }^{11}$, UM Das, (2009) ${ }^{14}$, Mahesh Kumar P (2005) ${ }^{18}$ and Deepak (2010) ${ }^{15}$ while contrasting results were reported by Josh et al(2003) ${ }^{12}$ and Dhar V (2007) ${ }^{13}$ who observed higher prevalence in girls. Boys suffered more than girls because the frequency of brushing and other oral hygiene habits seemed to be gender related. Girls are more concerned about their personal hygiene than boys. It might also be more difficult to change the behavior of boys than of girls, because girls tend to have more health directed behavior than boys. ${ }^{9}$

No significant difference was found in the distribution of disease according to the potable water source of the family.

Maximum (48.39\%) in the present study were found amongst children who cleaned their teeth with fingers followed by (40\%) children who used charcoal with fingers,(36.39\%) tooth brush and tooth powder, tooth brush and paste(25.41\%) and this variation was also found highly significant $(\mathrm{P}<0.001)$. The result of the present study are in concurrence with $\mathrm{P}$ Mahesh (2005). ${ }^{18}$

Toothbrush and toothpaste are used to maintain day to day oral hygiene and good oral hygiene status was found to be significantly correlated with better periodontal health. These are mechanical aids which help in removing the microbial plaque in daily routine which in turn are responsible for good oral hygiene as well as less prevalence of periodontal diseases. ${ }^{13}$

More frequent brushing tends to give better plaque control and improved gingival health. Brushing helps to control the plaque and bacteria that cause dental disease. If plaque is not removed, it turns into calculus. If plaque and calculus are not removed, they begin to destroy thegums and bone, causing periodontal disease.

CONCLUSION: Periodontal diseases were associated with rural areas, age sex and education of mother. Father's education and drinking water source were not associated with periodontal diseases. Although in oral hygienic practices, mouth rinsing and teeth cleaning frequency were not found to be associated in children but type of teeth cleaning materials used were associated with periodontal diseases. Those who used fingers for cleaning their teeth were having more chances of periodontal diseases.

\section{REFERENCES:}

1. Khamrco TY. Assessment of periodontal disease using the CPITN index in a rural population in Ninevah, Iraq. Eastern Mediterranean Health Journal, 1999; 5 ( 3) : 549555.

2. Singhal J.P. An Epidemiological Study of Dental and Periodontal diseases among school children in Ajmer City. Thesis submitted for the degree of MD. (P.S.M.), University of Rajasthan 1981.

3. World Health Organizations. WHO Information Series on School Health, Document Eleven. World Health Organization 2003. Geneva, Switzerland) http:// new.paho.org/hq/dmdocuments/ 2009 / OH_ st_ sch.pdf.

4. Jain, D.C. An epidemiological study of dental and periodontal disease in a group of villages in the area of rural health training centre, Naila (Jaipur). Thesis submitted for the Degree of Doctor of Medicine (Preventive and Social Medicine), University of Rajasthan, 1979. 
5. Rao SP, Bharambe MS. Dental Caries and Periodontal Disease among Urban. Rural and Tribal School Children. Indian Pediatrics 1993; 30 (6) : 759-764.

6. Peter S. Essentials of Preventive and Community Dentistry. 2nd edition. New Delhi; Arya Medi Publications, 2004.

7. World Health Organization. Oral Health Surveys - Basic Methods; WHO 2004.

8. Benoît Varenne. Oral health status of children and adults in urban and rural areas of Burkina Faso, Africa International Dental Journal. 2004; 54: 83-89.

9. Aiste Zaborskyte, Egle Bendoraitiene Oral Hygiene Habits and Complaints of Gum Bleeding among School children in Lithuania Stomatologija, 2003; Vol. 5, No. 1.

10. Poornima Tiwari et al. Dental fluorosis and its association with the use of fluoridated toothpaste among middle school students of Delhi. 2010; 64(1): 1-6.

11. Goel P et al. Prevalence of dental disease amongst 5-6 and 12-13 year old school children of Puttur municipality, Karnataka State-India. J Indian Soc Pedo Prev Dent. 2000 Mar; 18 (1): 11-7.

12. Jose A. Prevalence of dental health problems among school going children in rural Kerala. J. Indian Soc Pedo Prev Dent. 2003; 21 : 147-151

13. Dhar V et al. Prevalence of gingival diseases, malocclusion and fl uorosis in school-going children of rural areas in Udaipur district. J Indian Soc Pedod Prev Dent - June 2007.

14. Das UM et al. Oral health status of 6- and 12-year-old school going children in Bangalore city : an epidemiological study. J Indian Soc Pedod Prev Dent. 2009 Jan-Mar; 27 (1): 6-8.

15. Deepak et al. Study of oral hygiene status and prevalence of gingival diseases in 10-12 year school children in Maharashtra. Journal of International Oral Health 2010; vol 2, issue 3.

16. S Saravanan. Prevalence of Dental Flurosis Among Primary School Children in Rural Areas of Chidambaram Taluk, Cuddalore District, Tamil Nadu, India Indian Journal of Community Medicine, Vol. 33, Issue 3, July 2008.

17. Harshal T Pandve. Recent advances in oral health care in India. 2009; Volume 20 : Issue $1: 129-130$

18. Mahesh Kumar P et al. Oral health status of 5 years and 12 years school going children in Chennai city : An epidemiological study. J Indian Soc Pedo Prev Dent 2005; 23 : 17-22.

Table no. I

\begin{tabular}{|c|c|c|c|c|}
\hline S. No. & Area & Total $(\mathrm{N}=3200)$ & Periodontal Cases & $\begin{array}{l}\text { Chi-Square Test } \\
\text { P Value LS }\end{array}$ \\
\hline 1 & Rural & 1600 & 553 & \multirow{2}{*}{$\begin{array}{l}28.629 \text { at } 1 \text { DF } \\
\mathrm{P}<.001 \text { HS }\end{array}$} \\
\hline 2 & Urban & 1600 & 385 & \\
\hline S. No. & \multicolumn{4}{|c|}{ Age group (in years) } \\
\hline 1 & 5 to 7 & 536 & 44 & \multirow{4}{*}{$\begin{array}{l}222.63 \text { at } 3 \text { DF } \\
\mathrm{P}<.001 \text { HS }\end{array}$} \\
\hline 2 & 8 to 10 & 1098 & 269 & \\
\hline 3 & 11 to 13 & 1362 & 563 & \\
\hline 4 & 14 to 16 & 204 & 62 & \\
\hline
\end{tabular}




\section{ORIGINAL ARTICLE}

\begin{tabular}{|c|c|c|c|c|}
\hline & \multicolumn{4}{|l|}{ Sex Wise } \\
\hline 1 & Male & 1632 & 547 & \multirow{2}{*}{$\begin{array}{l}28.243 \text { at } 1 \text { DF } \\
\mathrm{P}<.001 \text { HS }\end{array}$} \\
\hline 2 & Female & 1570 & 391 & \\
\hline S. No. & \multicolumn{4}{|l|}{ Father's Education } \\
\hline 1 & Illiterate & 678 & 220 & \multirow{7}{*}{$\begin{array}{l}10.785 \text { at } 6 \text { DF } \\
P=0.95 \mathrm{NS}\end{array}$} \\
\hline 2 & Primary & 551 & 166 & \\
\hline 3 & Middle & 652 & 194 & \\
\hline 4 & Secondary & 739 & 214 & \\
\hline 5 & Higher secondary & 366 & 94 & \\
\hline 6 & Graduation & 171 & 43 & \\
\hline \multirow[t]{2}{*}{7} & Post graduation & 43 & 7 & \\
\hline & \multicolumn{4}{|l|}{ Mother's Education } \\
\hline 1 & Illiterate & 1954 & 962 & \multirow[b]{7}{*}{$\begin{array}{l}53.065 \text { at } 6 \text { DF } \\
\mathrm{P}<.001 \mathrm{HS}\end{array}$} \\
\hline 2 & Primary & 498 & 189 & \\
\hline 3 & Middle & 376 & 131 & \\
\hline & Secondary & 265 & 95 & \\
\hline 5 & Higher secondary & 81 & 34 & \\
\hline 6 & Graduation & 36 & 11 & \\
\hline 7 & Post graduation & 17 & 10 & \\
\hline
\end{tabular}

Table no. II

\begin{tabular}{|c|c|c|c|c|}
\hline S.NO. & Water Source & Total (3200) & Periodontal Cases & $\begin{array}{l}\text { Chi-Square Test } \\
\text { P Value LS }\end{array}$ \\
\hline 1 & Tap & 2325 & 657 & \multirow{4}{*}{$\begin{array}{l}7.127 \text { at } 3 \mathrm{DF} \\
\mathrm{P}=0.089 \mathrm{NS}\end{array}$} \\
\hline 2 & Handpump & 347 & 117 & \\
\hline 3 & Tubewell & 480 & 145 & \\
\hline 4 & Well & 48 & 19 & \\
\hline S.No. & \multicolumn{4}{|l|}{ Mouth Rinsing per Day } \\
\hline 1 & Never & 943 & 252 & \multirow{3}{*}{$\begin{array}{l}4.738 \text { at } 2 \mathrm{DF} \\
\mathrm{P}=0.094 \mathrm{NS}\end{array}$} \\
\hline 2 & Sometime & 1947 & 587 & \\
\hline 3 & Always after meals & 310 & 99 & \\
\hline S.No. & \multicolumn{4}{|l|}{ Teeth Cleaning Material } \\
\hline 1 & Fingers & 248 & 120 & 76.303 at $5 \mathrm{DF}$ \\
\hline
\end{tabular}


ORIGINAL ARTICLE

\begin{tabular}{|c|c|c|c|c|}
\hline 2 & Tooth brush and Tooth Paste & 2113 & 537 & \multirow[t]{5}{*}{$\mathrm{P}<.001 \mathrm{HS}$} \\
\hline 3 & Tooth brush and Tooth powder & 316 & 115 & \\
\hline 4 & Datun & 240 & 87 & \\
\hline 5 & Charcoal with finger & 45 & 18 & \\
\hline 6 & Don't Clean & 238 & 61 & \\
\hline S.No & \multicolumn{4}{|l|}{ Frequency of teeth cleaning } \\
\hline 1 & Zero & 238 & 61 & \multirow[b]{5}{*}{$\begin{array}{l}2.018 \text { at } 4 \mathrm{DF} \\
\mathrm{P}=0.733 \mathrm{NS}\end{array}$} \\
\hline 2 & $<1$ & 138 & 39 & \\
\hline 3 & Once & 1884 & 564 & \\
\hline 4 & Twice & 828 & 242 & \\
\hline 5 & $>$ Twice & 112 & 32 & \\
\hline
\end{tabular}

Figure 1

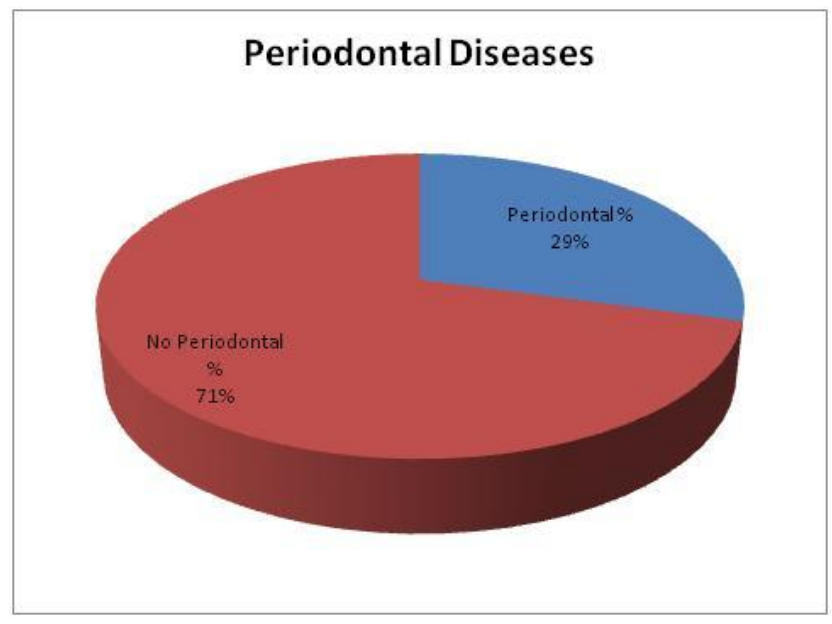

\section{AUTHORS:}

1. Rashmi Gupta

2. Kuseem Lata Gaur,

3. Akhil Sharma,

4. Afifa Zafer,

5. Dilip Raj.

\section{PARTICULARS OF CONTRIBUTORS:}

1. Demonstrater, Department of Preventive \& Social Medicine, SMS Medical College.

2. Professor, Department of Preventive \& Social Medicine, SMS Medical College.

3. Dentist, Balaji Clinic. Jaipur.

4. Professor, Department of Preventive \& Social Medicine, SMS Medical College.
5. Associate Professor, Department of Preventive $\&$ Social Medicine, SMS Medical College.

\section{NAME ADRRESS EMAIL ID OF THE} CORRESPONDING AUTHOR:

Dr. Kusum Lata Gaur,

'Divya Jeevan' 20, Kailashpuri,

Near Jagatpura Rly Station,

Jaipur(Raj) India.

E-mail: drkusumagaur@gmail.com

Date of Submission: 01/07/2013.

Date of Peer Review: 01/07/2013.

Date of Acceptance: 10/07/2013.

Date of Publishing: 15/07/2013 